\title{
Preliminary Study of Interaction of Clarithromycin with Tacrolimus in Cats
}

\author{
Masaaki KATAYAMA ${ }^{1) *}$, Taku USHIO'), Shunsuke SHIMAMURA ${ }^{2)}$, Yasuhiko OKAMURA ${ }^{3)}$ and Yuji UZUKA ${ }^{1)}$ \\ 1)Division of Veterinary Diagnostic Imaging, Cooperative Department of Veterinary Medicine, Faculty of Agriculture, Iwate University, \\ 3-18-8 Ueda, Morioka, Iwate 020-8550, Japan \\ ${ }^{2)}$ Veterinary Medical Center, Osaka Prefecture University, 1-58 Rinku-oraikita, Izumisano, Osaka 598-8531, Japan \\ ${ }^{3)}$ Division of Small Animal Surgery, Cooperative Department of Veterinary Medicine, Faculty of Agriculture, Iwate University, 3-18-8 \\ Ueda, Morioka, Iwate 020-8550, Japan
}

(Received 26 February 2014/Accepted 17 July 2014/Published online in J-STAGE 5 August 2014)

ABSTRACT. Tacrolimus (Tac) is a core immunosuppressive drug in human organ transplantation. In feline kidney transplantation, however, the cost of Tac therapy is a significant obstacle. Clarithromycin (CLM) increases the blood trough level of Tac, effectively reducing the Tac dosage in human transplant patients. The interaction between CLM and Tac in cats has not been reported. In this study, the effect of multiple CLM dosing on the pharmacokinetics of Tac in three healthy cats was investigated. The treatments included Tac at $0.3 \mathrm{mg} / \mathrm{kg}$ and Tac at $0.3 \mathrm{mg} / \mathrm{kg}+$ multiple-dose CLM at $10 \mathrm{mg} / \mathrm{kg}$. Co-administration of CLM and Tac resulted in significant increases in the oral bioavailability of Tac. These preliminary findings suggest that administration of multiple doses of CLM may decrease the required Tac dosage in Tac-based immunosuppressive therapy used as an alternative to the classic cyclosporine-based protocol for feline renal transplantation. KEY WORDS: clarithromycin, feline, kidney transplantation, pharmacokinetics, tacrolimus

doi: 10.1292/jvms.14-0101; J. Vet. Med. Sci. 76(11): 1527-1529, 2014

Immunosuppressive therapy with a combination of cyclosporine and prednisolone has led to successful kidney transplantation in feline patients with end-stage kidney failure [6]. There are currently no alternative immunosuppressive regimens available for individual cats that are difficult to manage with cyclosporine, such as those with cyclosporineassociated hemolytic uremic syndrome [1]. Tacrolimus (Tac) has been used as a core immunosuppressive drug for the prevention of acute allograft rejection in humans [13]. The immunosuppressive effects of Tac have also been shown in a feline kidney transplantation model [8]. In an in vitro study, Tac inhibited alloantigen- and mitogen-induced lymphocyte proliferation and interleukin-2 production five- to eightfold more potently than did cyclosporine in cats [9]. Interestingly, Tac also inhibited B-cell activation and antibody production, unlike cyclosporine [12]. Although Tac is considered to be a potential alternative to cyclosporine, the cost of Tac-based immunosuppressive therapy is a significant obstacle.

Tac is widely known as the substrate of cytochrome P450 (CYP) 3A and P-glycoprotein (P-gp) [14, 16]. When Tac is combined with the inhibitors of these proteins, Tac metabolism is affected to various degrees. In human patients undergoing heart and bone marrow transplantation, clarithromycin (CLM), an inhibitor of both CYP3A and P-gp,

*Correspondence to: Katayama, M., Division of Veterinary Diagnostic Imaging, Cooperative Department of Veterinary Medicine, Faculty of Agriculture, Iwate University, 3-18-8 Ueda, Morioka, Iwate 020-8550, Japan. e-mail: masaaki@iwate-u.ac.jp (C)2014 The Japanese Society of Veterinary Science

This is an open-access article distributed under the terms of the Creative Commons Attribution Non-Commercial No Derivatives (by-nc-nd) License $<$ http://creativecommons.org/licenses/by-nc-nd/3.0/>. significantly increased the Tac blood concentrations and thus reduced the Tac dosage $[4,7]$. Based on these findings, CLM may enhance the utility of Tac in feline kidney transplant patients by decreasing the therapeutic cost. In cats, however, whether CLM affects the oral bioavailability of Tac has not been reported. The aim of this study was to evaluate the effect of CLM on the Tac blood level in cats. We investigated the effects of multiple oral administration of CLM on the pharmacokinetics of Tac in healthy cats.

Three healthy male cats were used in this study. Their body weights ranged from 4.4 to $5.1 \mathrm{~kg}$, and their ages ranged from 3 to 4 years. Prior to this study, all cats were confirmed to be healthy based on the results of a physical examination, complete blood count, biochemical profile and urinalysis. Two treatments (A and B) were performed in each cat. Kyles et al. [8] reported that the appropriate dosage of Tac required to achieve trough whole blood concentrations within the target range $(5-10 \mathrm{ng} / \mathrm{m} l)$ in feline transplantation is 0.25 to $0.5 \mathrm{mg} / \mathrm{kg}$ BID. Therefore, the dose of Tac (Prograf Granules $0.2 \mathrm{mg}$; Astellas, Tokyo, Japan) was adjusted to $0.3 \mathrm{mg} / \mathrm{kg}$. In treatment group A, cats received single oral dose of Tac. In treatment group B, cats were given approximately $10 \mathrm{mg} / \mathrm{kg}$ of CLM (clarithromycin $50 \mathrm{mg}$ capsule; Chouseido, Tokushima, Japan) (range, 9.8-11.3 mg/kg; mean dose, $9.8 \mathrm{mg} / \mathrm{kg}$ ) once daily for 2 weeks (days 1-14) and Tac $2 \mathrm{hr}$ after CLM on day 15. The washout times of each treatment were $>1$ month. In this study, complete blood count, serum biochemical analysis and urinalysis were not repeated at the end of the study to confirm the adverse effects of the drugs. This study was approved by the Iwate University Animal Care and Use Committee (A201337).

Whole blood samples were drawn through the jugular vein at $0.5,1,2,4,6,8,12$ and $24 \mathrm{hr}$ after Tac administration and 
Table 1. Effects of multiple doses of oral clarithromycin (CLM) on the pharmacokinetic parameters of tacrolimus (Tac) in three healthy cats

\begin{tabular}{lcccccc}
\hline \multicolumn{1}{c}{ Parameters } & $\begin{array}{c}\mathrm{AUC}_{0-24} \\
(\mathrm{ng} \cdot \mathrm{h} / \mathrm{m} l)\end{array}$ & $\begin{array}{c}\mathrm{C}_{\max } \\
(\mathrm{ng} / \mathrm{m} l)\end{array}$ & $\begin{array}{c}\mathrm{T}_{\max } \\
(\mathrm{hr})\end{array}$ & $\begin{array}{c}\mathrm{T}_{1 / 2} \\
(\mathrm{hr})\end{array}$ & $\begin{array}{c}\mathrm{AUMC}_{0-24} \\
\left(\mathrm{ng} \cdot \mathrm{h}^{2} / \mathrm{m} l\right)\end{array}$ & $\begin{array}{c}\mathrm{MRT}_{0-24} \\
(\mathrm{hr})\end{array}$ \\
\hline Treatment A & $296.6 \pm 175.3$ & $46.0 \pm 13.4$ & $2.0 \pm 0.0$ & $13.3 \pm 2.5$ & $2326.6 \pm 1822.3$ & $7.9 \pm 0.7$ \\
Treatment B & $683.3 \pm 140.7^{*}$ & $79.0 \pm 9.6$ & $2.0 \pm 0.3$ & $15.4 \pm 8.5$ & $6516.8 \pm 1341.0$ & $9.2 \pm 0.2$ \\
\hline
\end{tabular}

Values are presented as means \pm SE. Treatment A: Tac $(0.3 \mathrm{mg} / \mathrm{kg}$ PO) alone. Treatment B: Tac $(0.3 \mathrm{mg} / \mathrm{kg}$ PO $)+$ multiple therapeutic doses of CLM $(10 \mathrm{mg} / \mathrm{kg} \mathrm{PO})$. *Significantly different from treatment group $\mathrm{A}(0.01<P<0.05)$.

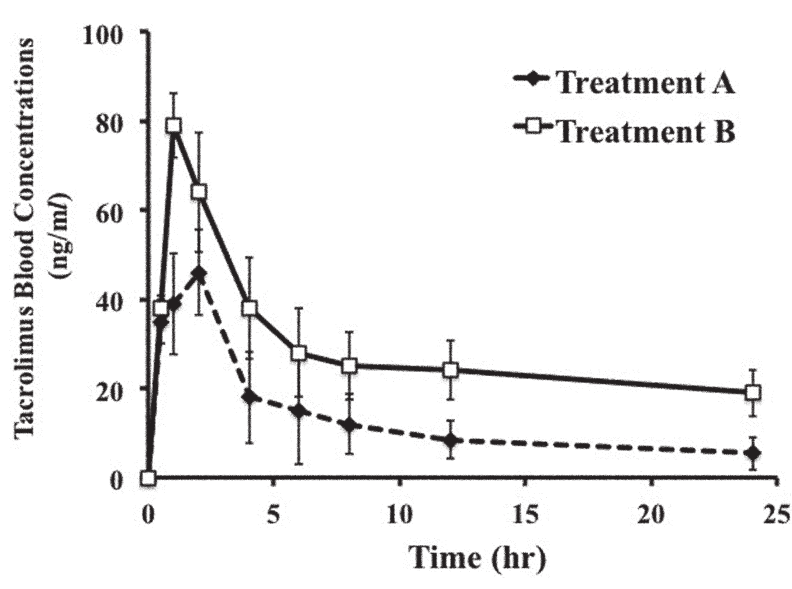

Fig. 1. Mean Tac blood concentration-time curves of the three healthy cats following treatment A (Tac alone) and treatment B $(\mathrm{Tac}+$ multiple therapeutic doses of CLM). Values are presented as means \pm SE.

were collected in tubes containing EDTA. Blood samples were stored overnight at $0^{\circ} \mathrm{C}$ until analysis. Measurement of the whole-blood Tac concentration was performed using a Pro-Trac II Tacrolimus ELISA kit (DiaSorin, Stillwater, MN, U.S.A.) by a commercial laboratory (SRL, Tokyo, Japan). The limit of quantitation in the whole-blood Tac concentrations was $0.5 \mathrm{ng} / \mathrm{ml}$ according to the commercial laboratory.

The maximum blood concentration $\left(\mathrm{C}_{\max }\right)$ and its corresponding time $\left(\mathrm{t}_{\max }\right)$ were determined for each cat by observation of the blood Tac concentration-versus-time profile. The area under the curve from 0 to $24 \mathrm{hr}\left(\mathrm{AUC}_{0-24}\right)$ after Tac administration was calculated by the linear trapezoidal method. The terminal elimination rate constant $(k)$ was calculated by linear least-squares regression analysis using the last 3 measurement points in the log-linear terminal phase. The $t_{1 / 2}$ was estimated as $0.693 / k$. The area under the first-moment curve from 0 to $24 \mathrm{hr}\left(\mathrm{AUMC}_{0-24}\right)$ after Tac administration was also calculated by the linear trapezoidal method. The mean residence time from 0 to $24 \mathrm{hr}\left(\mathrm{MRT}_{0-24}\right)$ was calculated as $\mathrm{AUMC}_{0-24} / \mathrm{AUC}_{0-24}$.

Differences in the pharmacokinetic parameters between each treatment were analyzed using the paired $t$-test and were regarded to be statistically significant at $P<0.05$. Each value is shown as the mean $\pm \mathrm{SE}$.

The blood concentration-time curves after the 2 treatments are shown in Fig. 1. The $\mathrm{AUC}_{0-24}$ of cats with CLM treatment (treatment B) was significantly higher than that of cats treated with Tac alone (treatment A) $(P<0.05)$. The mean Tac blood concentrations in cats with treatment B tended to be substantially higher than those in cats with treatment A. Pre-administration of multiple doses of CLM did not significantly affect $\mathrm{C}_{\max }, \mathrm{t}_{\max }, \mathrm{t}_{1 / 2} \mathrm{AUMC}_{0-24}$ or $\mathrm{MRT}_{0-24}$. The pharmacokinetic parameters of Tac with or without CLM are listed in Table 1.

Tac is metabolized by CYP3A and P-gp in the liver and small intestine [3]. In humans, oral Tac metabolism is reportedly dependent upon the small intestine rather than the liver [2]. In this study, co-administration of CLM and Tac resulted in a significantly higher $\mathrm{AUC}_{0-24}$ than did administration of Tac alone. We found no statistically significant differences in $\mathrm{t}_{1 / 2}$ or $\mathrm{MRT}_{0-24}$ of Tac between the 2 treatment groups. These findings indicate that the administration of multiple doses of CLM may increase the oral bioavailability of Tac in cats, mainly by decreasing the first-pass effect through CYP3A and/or P-gp inhibition.

Our results indicate that CLM use may reduce the dosage, cost and administration frequency of Tac in cats. These reductions would be of clinical importance in making renal transplantation more acceptable for pet owners. Prophylactic use of CLM may be beneficial for the prevention of bacterial infectious complications in feline kidney transplantation. In our previous study, long-term use of CLM was well tolerated without apparent adverse effects or complications, such as the development of antibiotic-resistant bacteria, in a feline kidney transplant patient [5]. On the other hand, Tac was administered as a single dose in this study, and the safety of the long-term use of Tac was not investigated. Therefore, a further study is needed to investigate the effectiveness and safety of long-term co-administration of Tac with CLM for feline kidney transplantation.

Besides the effects on Tac blood levels, CLM inhibits the production of IL-2 by human T cells in a dose-dependent manner, indicating that the immunosuppressive effects of CLM may be based partially on the ability to inhibit the production of IL-2 by T cells [11]. Co-administration of CLM with Tac may reinforce the immunosuppressive effects on T-cell proliferation developing to acute allograft rejection. CLM might be beneficial in feline kidney transplant recipients due to its immunosuppressive effects, thereby minimizing potential insults to the allograft.

Furthermore, Tac appears to have less severe effects on the proliferation and function of human regulatory $\mathrm{T}$ cells than cyclosporine according to an in vitro study [10]. Regulatory $\mathrm{T}$ cells are considered to be critical for the long-term protec- 
tion of the allograft against transplant rejection. Detection of high levels of regulatory $\mathrm{T}$ cells in the peripheral blood was associated with better graft outcome in human kidney transplant patients [15]. Although there are no reports regarding regulatory $\mathrm{T}$ cells in feline renal transplant patients, Tac may become an excellent alternative to cyclosporine on this point.

In conclusion, these preliminary findings show that CLM significantly increases the oral bioavailability of Tac in healthy cats and suggest that co-administration of Tac with multiple oral dosing of CLM may decrease the Tac dosage and dose frequency required for the prevention of acute allograft rejection. Further studies of the impact of CLM on Tac dosage are needed before applying combination therapy comprising Tac and CLM to feline renal transplant patients, because of the small number of animals used in this study.

\section{REFERENCES}

1. Aronson, L. R. and Gregory, C. R. 1999. Possible hemolytic uremic syndrome in three cats after renal transplantation and cyclosporine therapy. Vet. Surg. 28: 135-140. [Medline] [CrossRef]

2. Floren, L. C., Bekersky, I., Benet, L. Z., Mekki, Q., Dressler, D., Lee, W., Roberts, J. P. and Hebert, M. F. 1997. Tacrolimus oral bioavailability doubles with coadministration of ketoconazole. Clin. Pharmacol. Ther 62: 41-49. [Medline] [CrossRef]

3. Hebert, M. F. 1997. Contributions of hepatic and intestinal metabolism and P-glycoprotein to cyclosporine and tacrolimus oral drug delivery. Adv. Drug Deliv. Rev. 27: 201-214. [Medline] [CrossRef]

4. Ibrahim, R. B., Abella, E. M. and Chandrasekar, P. H. 2002. Tacrolimus-clarithromycin interaction in a patient receiving bone marrow transplantation. Ann. Pharmacother. 36: 1971-1972. [Medline] [CrossRef]

5. Katayama, M., Nishijima, N., Okamura, Y., Katayama, R., Yamashita, T., Kamishina, H. and Uzuka, Y. 2012. Interaction of clarithromycin with cyclosporine in cats: pharmacokinetic study and case report. J. Feline Med. Surg. 14: 257-261. [Medline] [CrossRef]

6. Katayama, M. and McAnulty, J. 2002. Renal Transplantation in Cats: Techniques, Complications, and Immunosuppression.
Compend. Contin. Educ. Pract. Vet. 24: 874-882.

7. Kunicki, P. K. and Sobieszczańska-Małek, M. 2005. Pharmacokinetic interaction between tacrolimus and clarithromycin in a heart transplant patient. Ther. Drug Monit. 27: 107-108. [Medline] [CrossRef]

8. Kyles, A. E., Gregory, C. R., Craigmill, A. L., Griffey, S. M., Jackson, J. and Stanley, S. D. 2003. Pharmacokinetics of tacrolimus after multidose oral administration and efficacy in the prevention of allograft rejection in cats with renal transplants. Am. J. Vet. Res. 64: 926-934. [Medline] [CrossRef]

9. Kyles, A. E., Gregory, C. R. and Craigmill, A. L. 2000. Comparison of the in vitro antiproliferative effects of five immunosuppressive drugs on lymphocytes in whole blood from cats. Am. J. Vet. Res. 61: 906-909. [Medline] [CrossRef]

10. Miroux, C., Morales, O., Ghazal, K., Othman, S. B., de Launoit, Y., Pancré, V., Conti, F. and Delhem, N. 2012. In vitro effects of cyclosporine A and tacrolimus on regulatory T-cell proliferation and function. Transplantation 94: 123-131. [Medline] [CrossRef]

11. Morikawa, K., Oseko, F., Morikawa, S. and Iwamoto, K. 1994. Immunomodulatory effects of three macrolides, midecamycin acetate, josamycin, and clarithromycin, on human T-lymphocyte function in vitro. Antimicrob. Agents Chemother. 38: 2643-2647. [Medline] [CrossRef]

12. Peters, D. H., Fitton, A., Plosker, G. L. and Faulds, D. 1993. Tacrolimus. A review of its pharmacology, and therapeutic potential in hepatic and renal transplantation. Drugs 46: 746-794. [Medline] [CrossRef]

13. Rath, T. 2013. Tacrolimus in transplant rejection. Expert Opin. Pharmacother. 14: 115-122. [Medline] [CrossRef]

14. Saeki, T., Ueda, K., Tanigawara, Y., Hori, R. and Komano, T. 1993. Human P-glycoprotein transports cyclosporin A and FK506. J. Biol. Chem. 268: 6077-6080. [Medline]

15. San Segundo, D., Fernández-Fresnedo, G., Rodrigo, E., Ruiz, J. C., González, M., Gómez-Alamillo, C., Arias, M. and LópezHoyos, M. 2012. High regulatory T-cell levels at 1 year posttransplantation predict long-term graft survival among kidney transplant recipients. Transplant. Proc. 44: 2538-2541. [Medline] [CrossRef]

16. Yokogawa, K., Takahashi, M., Tamai, I., Konishi, H., Nomura, M., Moritani, S., Miyamoto, K. and Tsuji, A. 1999. P-glycoprotein-dependent disposition kinetics of tacrolimus: studies in mdrla knockout mice. Pharm. Res. 16: 1213-1218. [Medline] [CrossRef] 